\title{
Rise in GPs taking early retirement
}

\author{
Tom Moberly UK editor
}

The BMJ

GPs are increasingly choosing to take early retirement, with the numbers doing so rising threefold over the past decade, data from NHS Digital show.

The number of GPs claiming their NHS pension on voluntary early retirement grounds increased from 198 in 2007-08 to 721 in 2016-17, and the number retiring on ill health grounds rose from 12 to 63 over the same period. Over the same period, the number retiring on age grounds fell by $60 \%$, from 944 in 2007-08 to 380 in 2016-17.

This has led to a shift in the proportions retiring for different reasons. In 2007-08, 82\% of doctors retired on age grounds, $17 \%$ took voluntary early retirement, and $1 \%$ retired on ill health grounds. By 2016-17, the proportion retiring on age grounds had fallen to $33 \%$, while $62 \%$ took voluntary early retirements, and $5 \%$ retired on grounds of ill health.

Overall, the proportion of GPs choosing to retire fell between 2007 and 08 and $2016-17$, from $3.1 \%$ in $2007-08$ to $2.8 \%$ in 2016-17. This is largely because the number of doctors qualifying as GPs rose in this period and so the total number of GPs increased, from 37720 to 41 891. This means that, even though the total number of GPs retiring increased slightly, from
1154 in 2007-08 to 1164 in 2016-17, this represents a smaller proportion of all GPs.

Although more GPs are taking early retirement, they are not doing so earlier in their lives. From 2007 to 08 to 2016-17 the average age at which GPs claim their NHS pension on voluntary early retirement grounds remained steady, at 57 .

Earlier this month, Simon Stevens, the chief executive of NHS England, told MPs that changes to pension rules was adding to problems around shortages of GPs. "The department's evidence to the Review Body on Doctors' and Dentists' Remuneration has pointed out that one of the contributory factors is the broad change to the pensions system," he said.

In April 2016, there was a reduction in the amount of pension benefit that can be drawn from pension schemes, known as the lifetime allowance. The lifetime allowance was introduced in 2006 at a level of $£ 1.5 \mathrm{~m}(€ 1.72 \mathrm{~m} ; \$ 2.12 \mathrm{~m})$. It was then gradually increased and reached $£ 1.8 \mathrm{~m}$ in 2010 . A number of reforms since then have reduced the allowance, the most recent being a reduction to $£ 1 \mathrm{~m}$ in 2016. The Pensions Advisory Service has advised that people who are approaching this limit may want to take their pension early to avoid their benefits exceeding this limit. 


\section{Figures}

GPS TAKING EARLY RETIREMENT

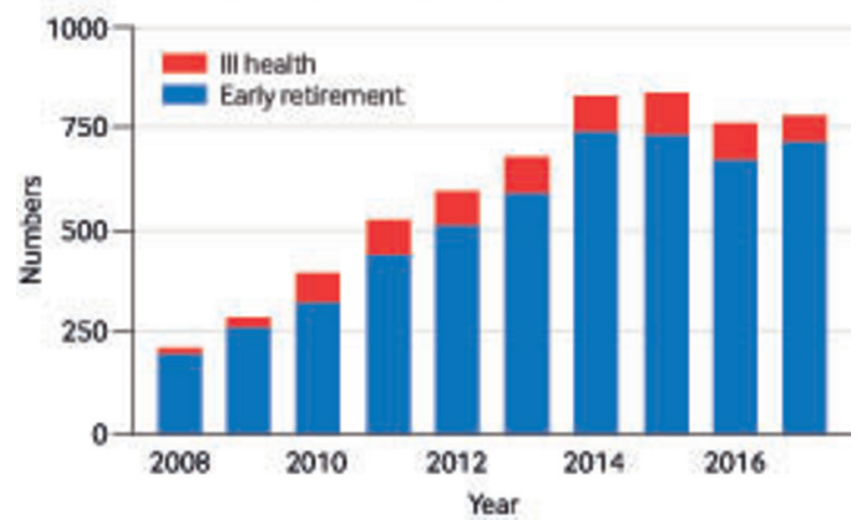

GPS RETIRING ON AGE GROUNDS

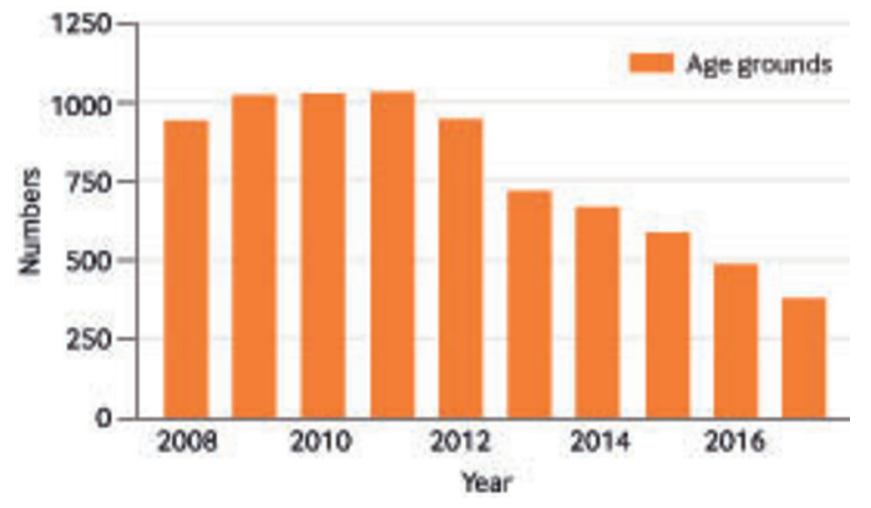

REASONS FOR RETIRING

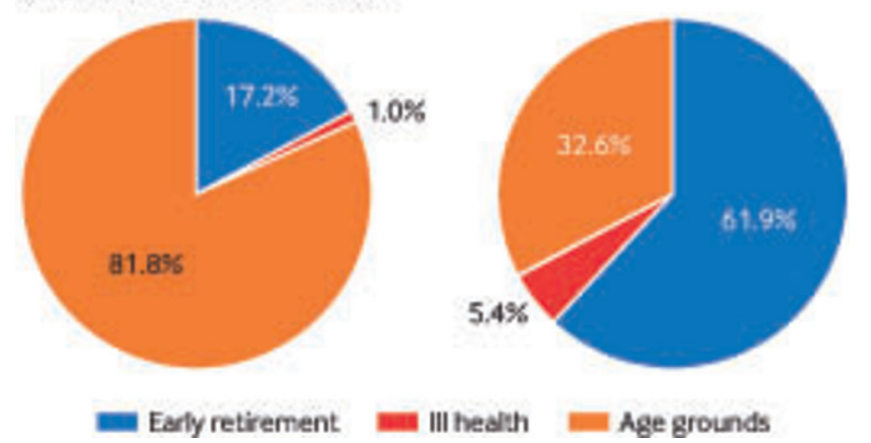

